\title{
Systolic time intervals and impedance cardiography
}

Sir,

The pair of papers from the New Delhi group (Balasubramanian et al. (1978), British Heart fournal, $40,268,276)$ are worthwhile contributions to the practical use of systolic time intcrvals based on impedance cardiography as well as providing interesting data on the effects of altitude. I take exception, however, to an important methodological aspect-correction of the pre-ejection period (PEP) for heart rate. Not only does pure rate change (atrial pacing) fail to change the PEP, but also a burgeoning literature (partially cited in Spodick, 1977) shows that any seeming pre-ejection periodheart rate (PEP-HR) relation is at best at very low level ( $r$ usually $\ll 0.2$ and nonsignificant) and, in any case, probably associated with a common factor (for example adrenergic stimulation) which affects both HR and PEP pari passu; that is, no direct relation. Indeed, the latest evidence of this appeared in the immediately preceding paper in the same number of the British Heart fournal (Wikstrand et al., 1978). This is of more than theoretical interest, particularly when one inspects Table 1 of the authors' paper on altitude effects. There, if the PEP is recalculated from the 'rate-corrected' PEP (by subtracting $0.44 \mathrm{HR}$ from the latter), there is almost no difference between the mean values and control PEP on all days excepting for small increases on days 5 and 10. The PEPs in ms from day one, 0 to $4 \mathrm{~h}$, to day 10 are as follows: $95,96,95,96,96,102,100$. After return to sea level the PEP was: 93, 94, 92. Similarly, in Table 2, the difference between sea-level PEP and day 10 at altitude is reduced from $17 \mathrm{~ms}$ ('rate-corrected') to only $6 \mathrm{~ms}$ (possibly significant but probably at a much lower level). Clearly, if, as so many contend, HR is not really related to PEP, there was little if any change in PEP. (On the other hand, if, as the authors imply, HR is related to PEP the changes in HR alone would account for most or all the altitude changes in PEP.)

I must also point out a misleadingly infelicitous turn of phrase in citing some of our work (Spodick and Lance, 1976). The authors state that we 'discussed the possibility' of eliminating the need for a phonocardiogram for recordings made during exercise performance. This is quite inaccurate. Far from discussing a 'possibility', we showed quite clearly that it can be done. Indeed, had the authors adopted this method, they might have solved some of their technical problems, including the problem of getting measurements during actual exercise performance. The argument that we used a peripheral pulse does not (as we demonstrated) affect the validity of the systolic time interval responses. Moreover, recent work has shown (Nandi and Spodick, 1977) that within the first 15 seconds after the conclusion of bicycle exercise the LVET continues to fall and then begins to rise. Thus, small differences among subjects in the exact timing of a post-exercise recording could produce widely divergent individual responses, impairing the validity of any group mean.

The foregoing considerations leave the body of information in these papers intact and show the utility of the impedance cardiogram. The authors and other workers may be interested in the proceedings of the Association for the Advancement of Medical Instrumentation (AAMI, Washington, D.C., March 1978). The session on impedance cardiography documented major advances in theory, technique, and applications.

David H. Spodick,

University of Massachusetts

Medical School,

Division of Cardiology,

St Vincent Hospital, Worcester, Mass. 01604, USA.

\section{References}

Nandi, P. S., and Spodick, D. H. (1977). Recovery from exercise at varying work loads: time-course of responses of heart rate and systolic intervals. British Heart fournal, 39, 958-966.

Spodick, D. H. (1977). Measurement of cardiac pre-ejection period. New England Fournal of Medicine, 296, 822-823.

Spodick, D. H., and Lance, V. Q. (1976). Noninvasive stress testing. Methodology for elimination of the phonocardiogram. Circulation, 53, 673-676.

Wikstrand, J., Berglund, G., Wilhelmsen, L., and Wallertin, I. (1978). Value of systolic and diastolic time intervals. British Heart fournal, 40, 256-267. 
This letter was shown to Dr Balasubramanian who replies as follows:

Sir,

We are grateful to Professor Spodick for drawing our attention to his views regarding correction of PEP for heart rate. This is controversial and it can hardly be said that there is a 'burgeoning' literature against correcting PEP for heart rate. Weissler et al. have always been advocating correction of PEP for heart rate and confirm it in all their recent reviews (Weissler et al., 1968; Lewis et al., 1974; Weissler, 1978); similarly, Salcedo and Siegel (1976) also advocate correction of PEP in their monograph on noninvasive cardiac diagnosis. They also point out that when atrial pacing is employed to increase the heart rate PEP does not shorten. Lewis and colleagues (1977) also advocate correction of PEP for heart rate. We, therefore, corrected PEP for heart rate as recommended by these workers.

We are fully aware of the pioneering contributions of Professor Spodick and his group in noninvasive cardiology for the past two decades, and have great esteem for him and his work. The 'misleadingly infelicitous turn of phrase' in citing Professor Spodick's work was totally unintentional.

V. Balasubramanian, Cardiology Department, Northwick Park Hospital and Clinical Research Centre, Watford Road, Harrow, Middlesex.

\section{References}

Lewis, R. P., Leighton, R. F., Forester, W. F., and Weissler, A. M. (1974). Systolic time intervals. In Noninvasive Cardiology, pp. 301-368. Ed. by A. M. Weissler. Grune and Stratton, New York.

Lewis R. P., Rittgers, S. E., Forester, W. F., and Boudoulas, H. (1977). A critical review of systolic time intervals. Circulation, 56, 146-158.

Salcedo, E. E., and Siegel, W. (1976). Systolic time intervals. In Noninvasive Cardiac Diagnosis, pp. 217-228. Ed. by E. K. Chung. Lea and Febiger, Philadelphia.

Weissler, A. M. (1978). Current concepts in cardiologySystolic time intervals. New England fournal of Medicine, 296, 321-324.

Weissler, A. M., Harris, W. S., and Schoenfeld, C. D. (1968). Systolic time intervals in heart failure in man. Circulation, 37, 149-159. 